\title{
Experimental Evaluation of Hybrid Cycloconverters
}

\author{
Christian Klumpner Tianning Xu Jon Clare \\ Department of Electrical and Electronic Engineering \\ University of Nottingham \\ Nottingham NG7 2RD, UNITED KINGDOM \\ Email: klumpner@ieee.org
}

\begin{abstract}
Power converters consisting of naturally commutated thyristors such as cycloconverters and current source inverters were the first used in driving electrical motors with variable speed but now due to their inferior performance compared to forced commutated converters, their use is restricted in the high voltage/high power range where the performance and cost of forced commutated switching devices is not competitive yet. Hybrid cycloconverters proposed recently improve the performance of cycloconverters by adding an auxiliary forced commutated inverter with reduced installed power that enhances the control over the circulating current and improves the quality of the output voltage. This paper evaluates the performance of a few standard and hybrid cycloconverter arrangements using simulation and experimental results.
\end{abstract}

\section{INTRODUCTION}

A cycloconverter [1]-[9] comprises of a network of naturally commutated thyristors that bidirectionally connect each of the input lines to each of the output lines as Fig. 1 shows. There are many topologies in use depending on the number of pulses of the thyristor bridges (6-12-18-24 etc) and if their operation relies on circulating current or not. The output voltage is controlled by modulating the firing angle to generate an AC output voltage of adjustable frequency and amplitude. Even though the operation is straightforward, there are some disadvantages, particularly a high content of harmonics in the output voltage and input current, dependent on the number of pulses. The higher the number of pulses, the better the generated waveform, but this is at the expense of increased complexity. This can be achieved by employing a multiphase (more than 3 phase) supply with has a smaller phase displacement between the supply phase voltages or by using phase-shifting transformers (delta-star or autotransformers) in a standard three-phase supply. The drawback of using a high number of pulses is that the assembly requires a large number of devices and it is rather bulky, as the transformers are designed for full power.

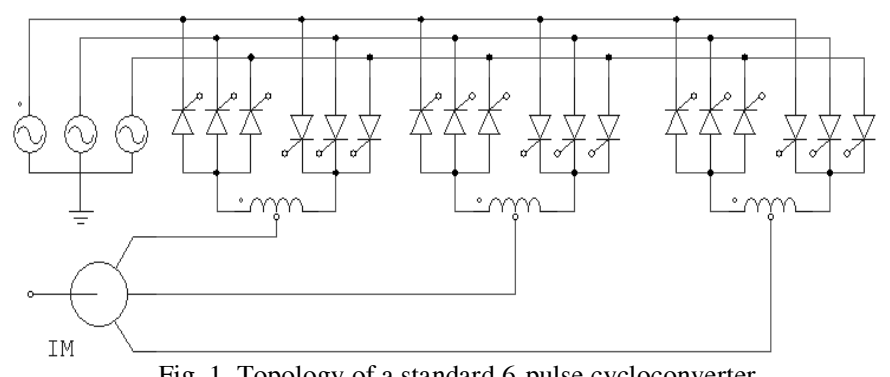

Fig. 1. Topology of a standard 6-pulse cycloconverter.
The main disadvantage of the cycloconverter is that the output frequency is usually limited to less than $40 \%$ of the input frequency and that the circuit has a poor input power factor due to the high content of harmonics and sub-harmonics in the input current. Also the poor control over the circulating current can cause additional distortion of the load current and further degrade the power quality on the input side. All existing solutions to mitigate these problems are exclusively based on passive components: phase shift transformers and inter-phase reactors (IPR) and as a result they are bulky, as the size of magnetics is dependent on the frequency of the ripple (number of pulses). However, this solution is still used in the very high power range (tens-hundreds MW) drives, where there is no other type of semiconductor switch available.

This paper evaluates the standard and the newly proposed hybrid cycloconverter [10] arrangements that can mitigate these problems by connecting an H-bridge inverter with lower voltage rated devices in each of the output phases of the cycloconverter. By controlling it in a way similar to a series connected active filter, it is able to improve the shape of the output voltage an in addition, to control the circulating current with good accuracy whilst employing a smaller inductor size, which may improve the quality of the input currents.

\section{THE HYBRID CYCLOCONVERTER}

The key to reduce the size of magnetics is to increase the frequency and/or reduce the amplitude of the ripple by employing an auxiliary forced commutated power converter operating in a similar way to a series active filter [10]. This will be then able to reduce/cancel the low frequency ripple in the output voltage and facilitate accurate control over the circulating current by switching faster whilst being rated at only a fraction of the supply voltage.

\section{A. Hybrid Cycloconverter with Circulating Current}

Cycloconverters operating in circulating current mode are known to offer better output voltage waveform, because of the filtering effect provided by the IPR. Fig. 2a shows the topology of a 3-phase/1-phase hybrid cycloconverter using an asymmetric H-bridge inverter with a split DC-link capacitor. Each leg of the H-bridge inverter handles one direction of the load current and the circulating current. The topology will result in low number of forced commutated devices, but since now the load current, having typically a low frequency, passes through the split DC-link capacitors, will maximize their size. By adding an extra inverter leg to the auxiliary inverter, as 

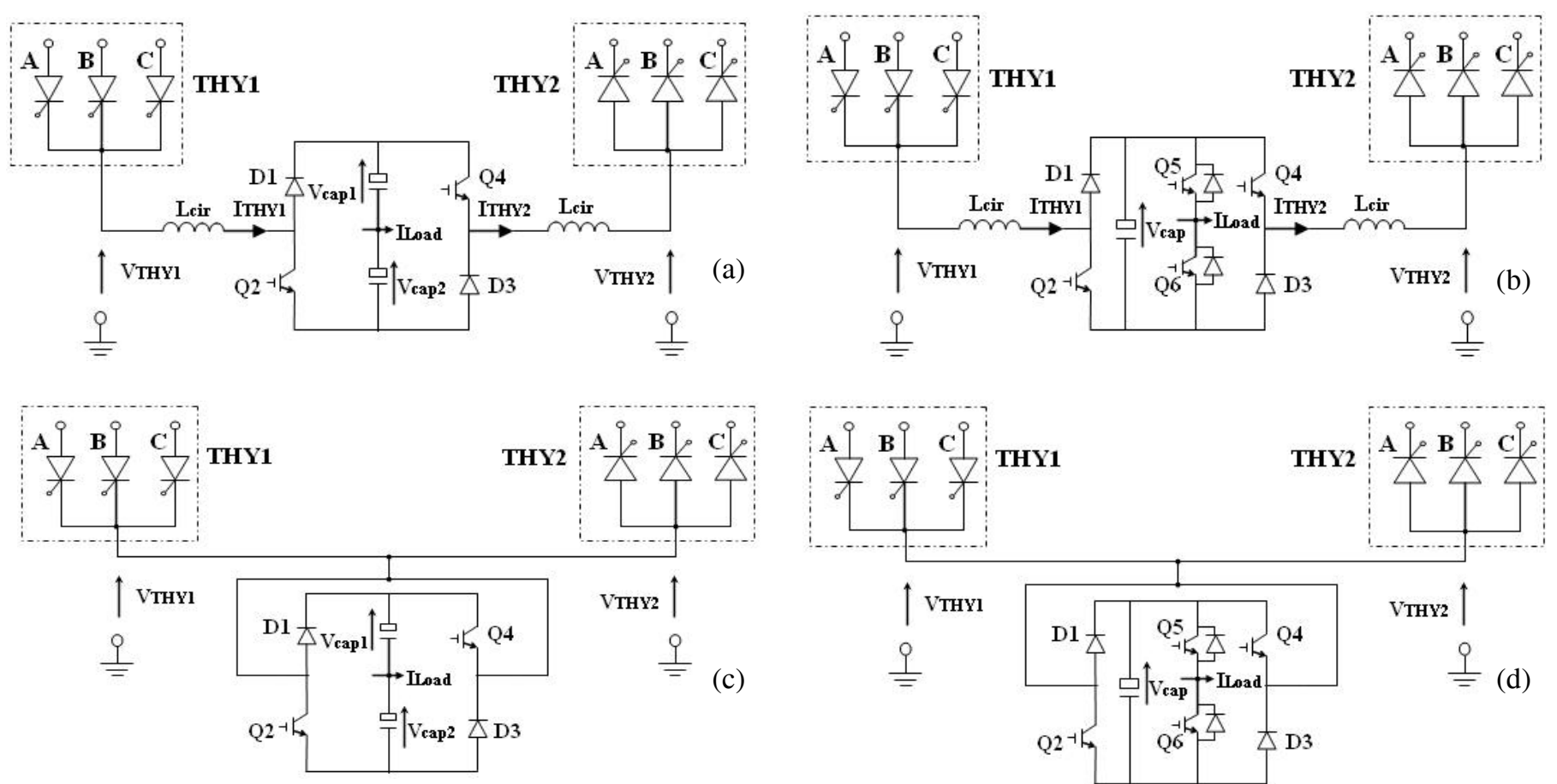

Fig. 2. Topologies of 3-phase/1-phase hybrid cycloconverters operating: a), b) in circulating current mode; c, d) in circulating current-free mode and using a), c) a split DC-link capacitor; or b), d) a single DC-link capacitor

shown in Fig. 2b, it is possible to reduce the size of the DClink capacitor. However, by adopting this solution, it is not possible to reduce much the voltage ratings of the switches since in order to control the circulating current, it is necessary to match the DC-link voltage to the differential mode voltage generated by the two cycloconverter halves (THY1 and THY2) [11].

\section{B. Hybrid Cycloconverter without Circulating Current}

Cycloconverters operating in circulating current-free mode are known to offer a poorer output voltage waveform quality mainly because at any time, one of the cycloconverter halves (THY1 or THY2) is disabled. However, the lack of an IPR and of the circulating current means that the size can be kept low and the input power quality (mainly the reactive power consumed from the power grid) is improved compared to a cycloconverter with circulating current and a similar number of pulses. In a similar way, it is possible to derive two hybrid cycloconverters topologies that operate in circulating currentfree mode. Fig. 2c shows the topology using an asymmetric Hbridge inverter with split DC-link, which is in fact a half bridge inverter, whilst in Fig. 2d, a full bridge inverter is used. The topologies have been depicted with two separate legs for each direction of the load current to suggest that the same auxiliary converters can be used, with very little changes to the circuit, to experimentally evaluate both types of hybrid cycloconverters. By comparing Fig. 2a,b with Fig. 2c,d, it is clear that the circulating current-free mode hybrid cycloconverter will have a simpler topology but only evaluating the load side and supply side performance will clarify which of the hybrid cycloconverters is actually better.

\section{Control of the Hybrid Cycloconverters}

The control structure of the hybrid cycloconverter which has been proposed and detailed in [10]-[11], is depicted in Fig. 3. It consists of three loops to control:

- the circulating current by calculating the differential mode voltage that needs to be injected by the H-bridge inverter;

- the output voltage by calculating the required common mode voltage that needs to be injected by the H-bridge inverter to cancel the output voltage ripple generated by the thyristor half bridges;

- the DC-link capacitor voltage of the H-bridge inverter by changing slowly the ratio of common mode demanded/generated by the cycloconverter that ultimately changes the net energy flow in the H-bridge DC-link.

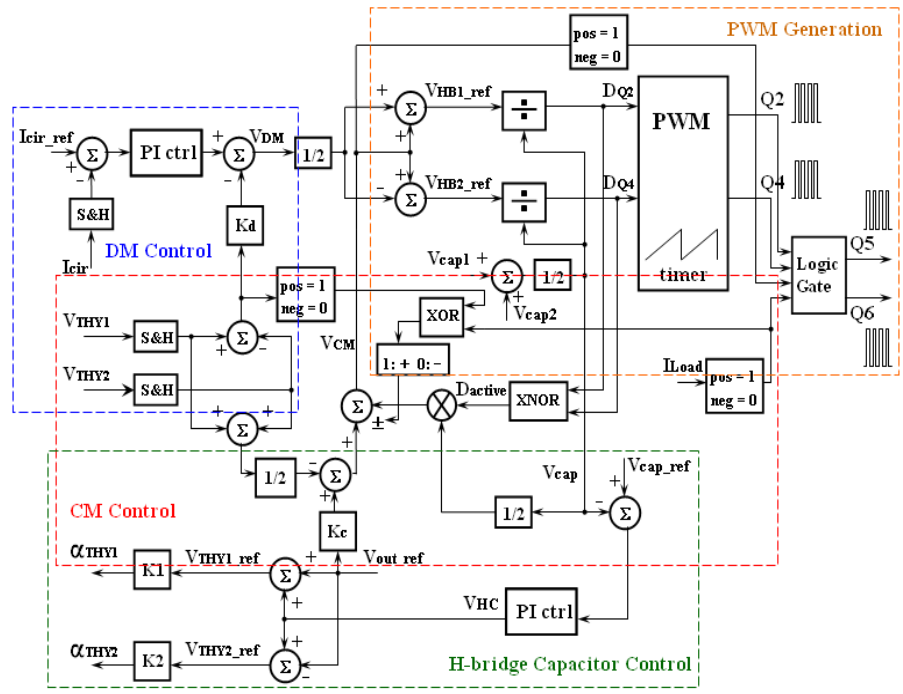

Fig. 3. Control structure of a hybrid cycloconverter. 


\section{SiMULATION RESULTS}

Simulation models of the standard and hybrid (only Fig. 2b and 2d) cycloconverters with and without circulating current have been implemented in SABER. The circuit parameters used in the simulation models are given in the Appendix A.

\section{A. Standard/Hybrid Cycloconverter with Circulating Current}

Fig. $4 \mathrm{a}$ and $4 \mathrm{~b}$ shows the output voltage generated by the two thyristor half bridges and Fig. 4c and 4d shows their FFT, revealing a $222 \mathrm{~V}_{\mathrm{pk}} @ 5 \mathrm{~Hz}$ common mode component. However, Fig. 4c and 4d (FFT) shows that the two half bridges generate also a large differential mode voltage, having the largest harmonic components $\left(185 \mathrm{~V}_{\mathrm{pk}}\right.$ and $\left.163 \mathrm{~V}_{\mathrm{pk}}\right)$ around $150 \mathrm{~Hz}$. This will cause circulating mode current that needs to be limited by the IPR, and sized accordingly, but not according to the differential mode voltage harmonic components around $150 \mathrm{~Hz}$, but according to the low frequency harmonics that are much difficult to predict.

Fig. 5 compares the load side performance of the standard vs. the hybrid cycloconverter operating with circulating current. Fig. 5a and 5c shows that by using the IPR, a clear improvement in the output waveform quality of a standard cycloconverter can be obtained. However, since the hybrid converter has added functionality, it can further reduce the low order voltage harmonic from approx. $75 \mathrm{~V}_{\mathrm{pk}}$ (around $150 \mathrm{~Hz}$ ) to a half (Fig. $5 \mathrm{~b}$ and $5 \mathrm{~d}$ ). The biggest improvement is obtained when analysing the circulating current (Fig. 5e and $5 \mathrm{~g}$ ), which can now be reduced and maintained to a minimum level (Fig. 5f and 5h) dictated by the thyristor's holding current given in the datasheet and may provide a much straightforward way of designing the IPR. Since the load is highly inductive, the improvement in the output voltage quality is not as obvious when looking at the waveform of the load current (Fig. 5i and 5j).

\section{B. Standard/Hybrid Cycloconverter w/O Circulating Current}

Fig. 6 shows by comparison the output performance of standard vs the hybrid cycloconverter that operate without circulating current. Fig. $6 \mathrm{a}$ and $6 \mathrm{~b}$ reveal that the output voltage waveform looks worse than for the standard cycloconverter with circulating current $\left(114 \mathrm{~V}_{\mathrm{pk}}\right.$ compared to $75 \mathrm{~V}_{\mathrm{pk}} @ 150 \mathrm{~Hz}$ ). However, the auxiliary $\mathrm{H}$-bridge inverter is able to improve the spectrum by reducing the harmonics around $150 \mathrm{~Hz}$ to approx $25 \mathrm{~V}_{\mathrm{pk}}$, better than in the previous case. This improvement is clearly visible also in the shape of the load current.

Fig. 7 shows the voltage injected by the auxiliary inverter of the hybrid cycloconverters when they operate with circulating current (Fig. 7a, only the voltage injected between the midpoint of one asymmetric leg and the output of the symmetric leg is shown) or without (Fig. 7b). It is seen that since for the circulating current-free mode cycloconverter, there is no differential mode voltage to be injected by the $\mathrm{H}$ bridge inverter, besides needing less power semiconductor devices, also the voltage stress is smaller ( $250 \mathrm{~V}$ compared to 320V).
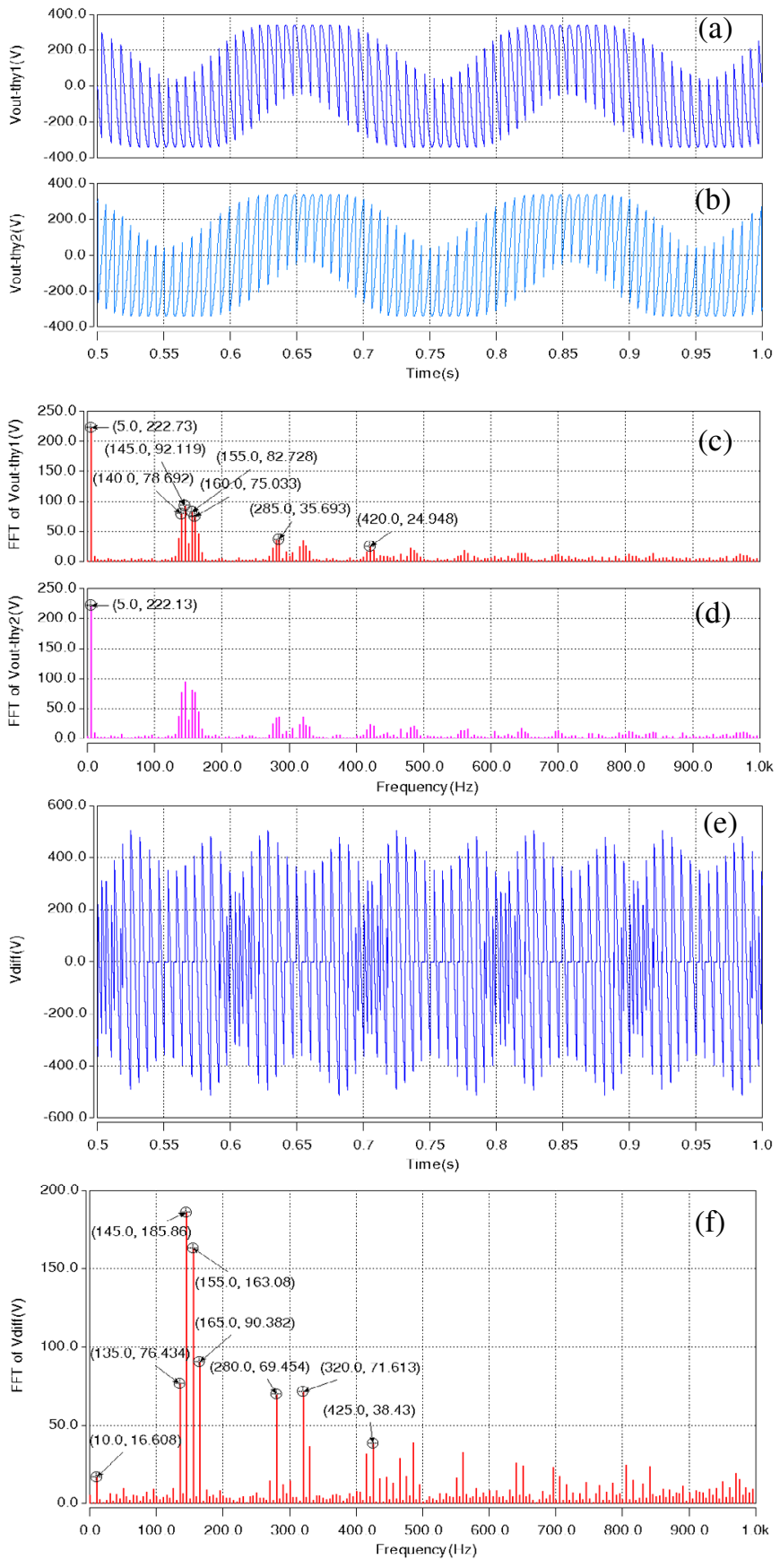

Fig. 4. Simulation results of a standard cycloconverter operating with circulating current: a), b) output voltage on each thyristor half bridge and c), d) the FFT; e) the differential mode voltage and f) the FFT.

\section{Input Side Performance}

Fig. 8 shows the waveform and the FFT of the input current for all these four situations: operation of the standard vs. the hybrid cycloconverter with and without circulating current. The only noticeable difference is that the standard cycloconverter with circulating current seems to draw a much larger input current at the fundamental frequency than the other three cases, which in conjunction to having the same load, and a very similar input current shape and harmonic profile, reveals that it consumes much more reactive power than the other three cycloconverter arrangements. 

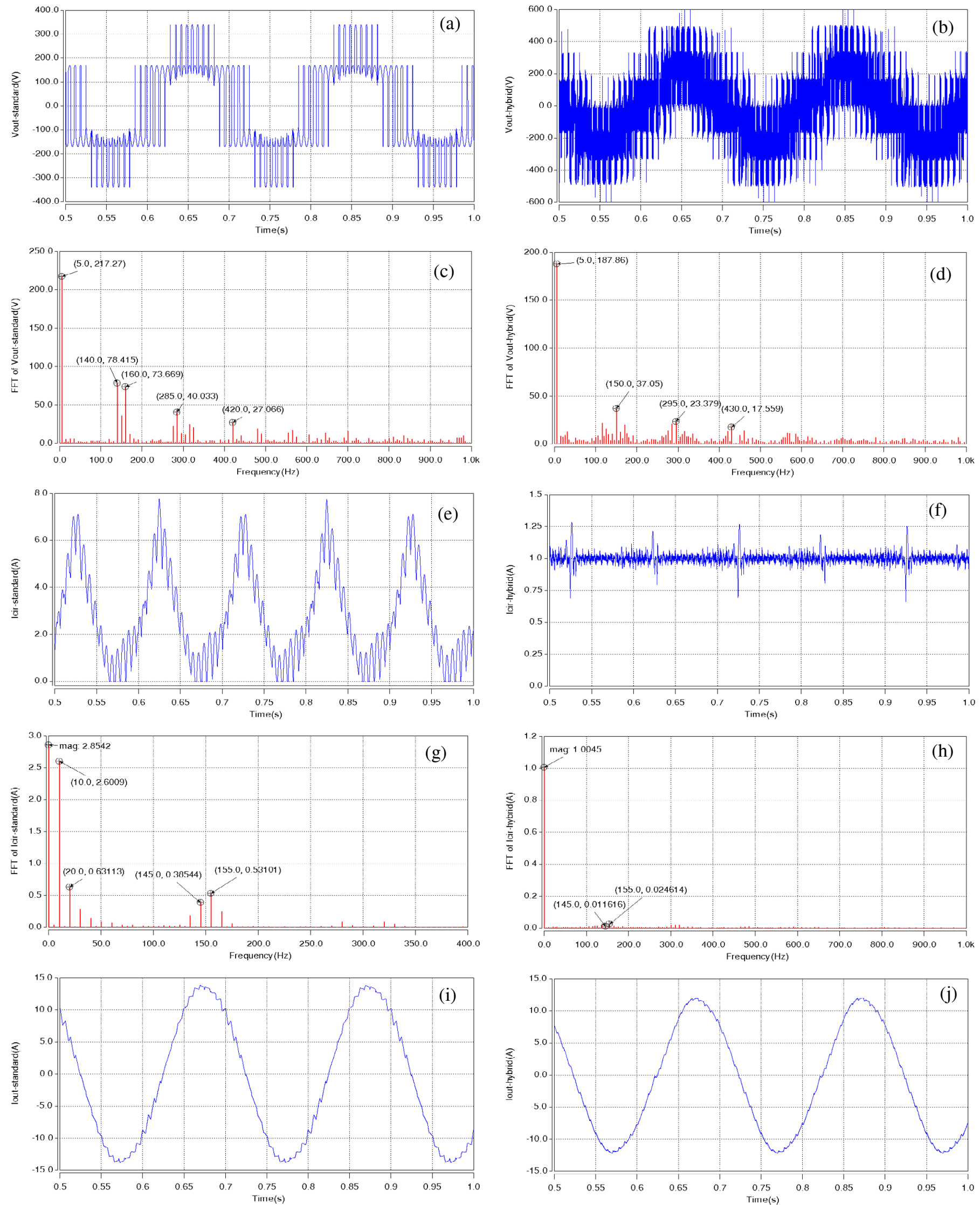

Fig. 5. Simulation results evaluating the performance of the standard vs. the hybrid cycloconverter that operate in circulating current mode: a), b) output voltage and c), d) its FFT; e), f) circulating current and g), h) its FFT; i), j) the load current 

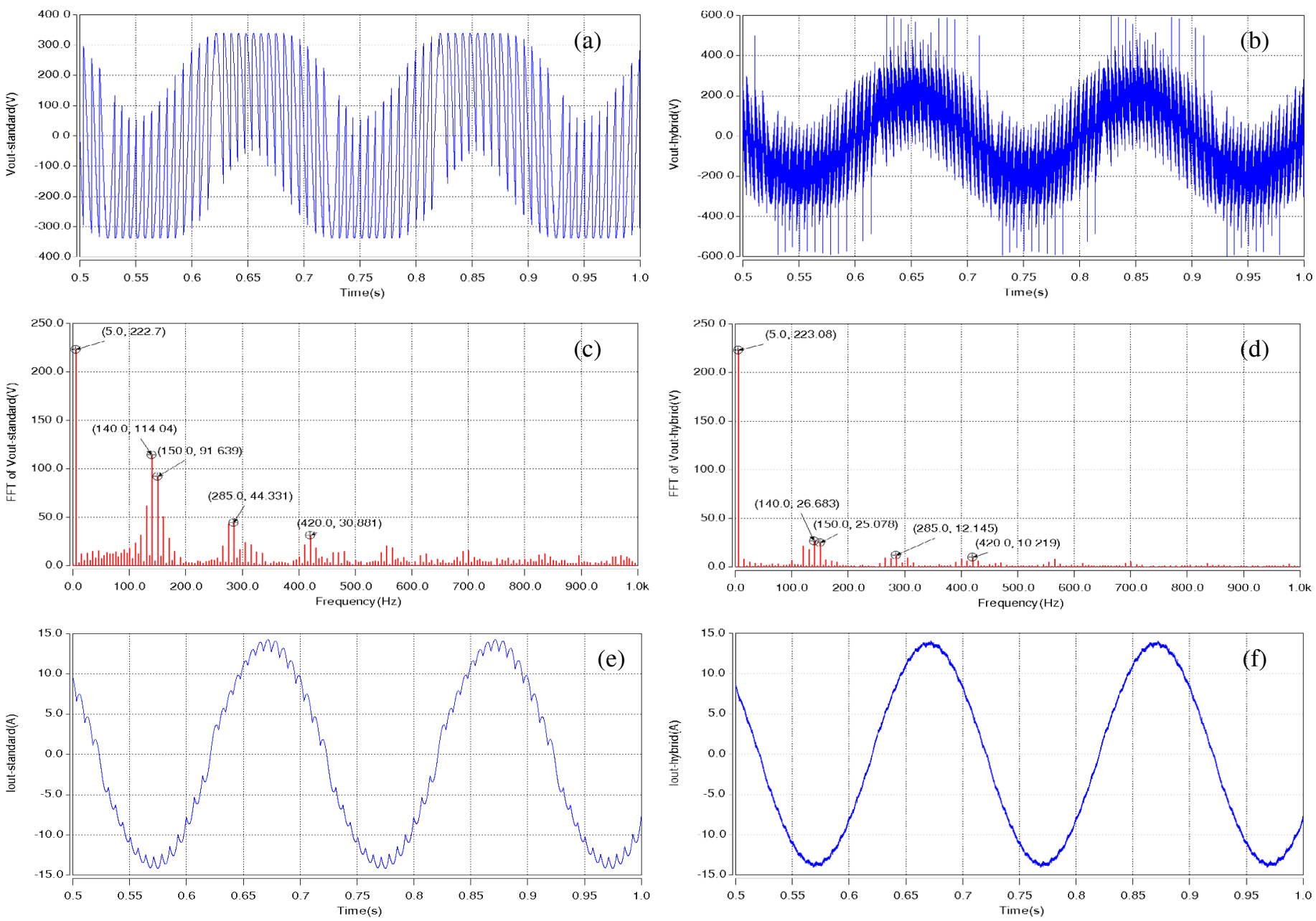

Fig. 6. Simulation results evaluating the performance of the standard vs. hybrid cycloconverter operating in circulating current-free mode: a), b) output voltage and c), d) its FFT; e), f) the load currents.
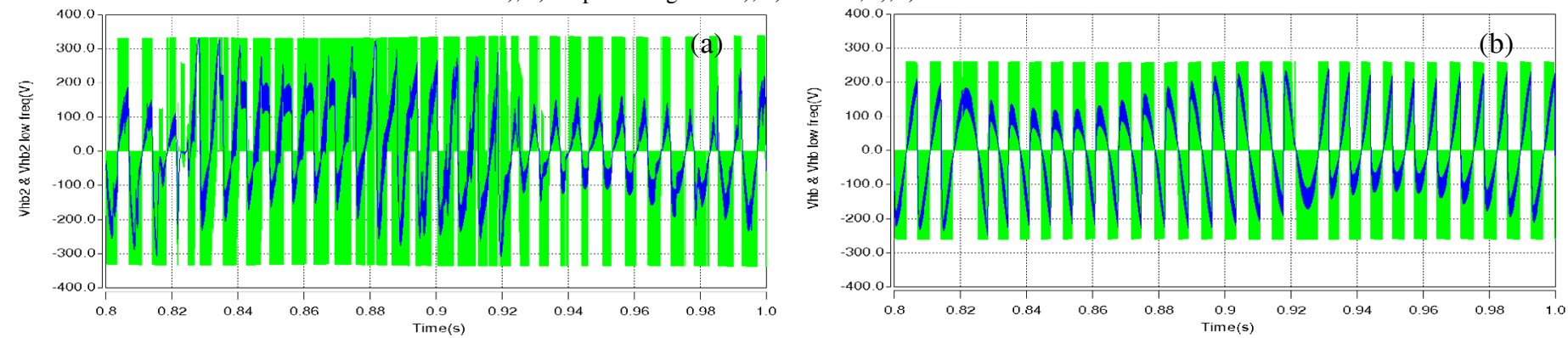

Fig. 7. PWM voltage and its reference injected by the auxiliary inverter of the hybrid cycloconverter operating in: a) circulating mode current (only the voltage between one asymmetric and the full leg is shown) and b) circulating current-free mode.

\section{EXPERIMENTAL RESULTS}

An experimental prototype is currently under development and at this stage, only experimental results with reduced input voltage (30\% of the rated value) were available to be included in the paper. The circuit parameters of the prototype are given in Appendix B. Fig. 9 shows the operation of the standard vs. hybrid cycloconverter with circulating current. The output voltage, the differential mode voltage delivered by the thyristor bridge and the load current are very similar to the simulation results: a reduction by $50 \%$ of the voltage harmonics (Fig. 9b and 9d) around $150 \mathrm{~Hz}$ and the presence of a sinusoidal load current waveform (Fig. 9e and 9f) which proves that the control is operating properly whilst the circulating current (Fig. 9g) measured here by disconnecting the load, is kept constant at $1 \mathrm{~A}$.

Fig. 10 shows the experimental results comparing the operation of the standard vs. hybrid cycloconverter in circulating current-free mode. Again, the output voltage waveforms (Fig. 10a and 10c) and spectrum (Fig. 10b and 10d) are very similar to the simulation results, showing an important reduction (to 30\%) of the most dominant harmonics (around 150Hz). The load current, however, shows some low order harmonic distortion caused by the errors in firing the incoming thyristors near the zero crossing of the load current, 

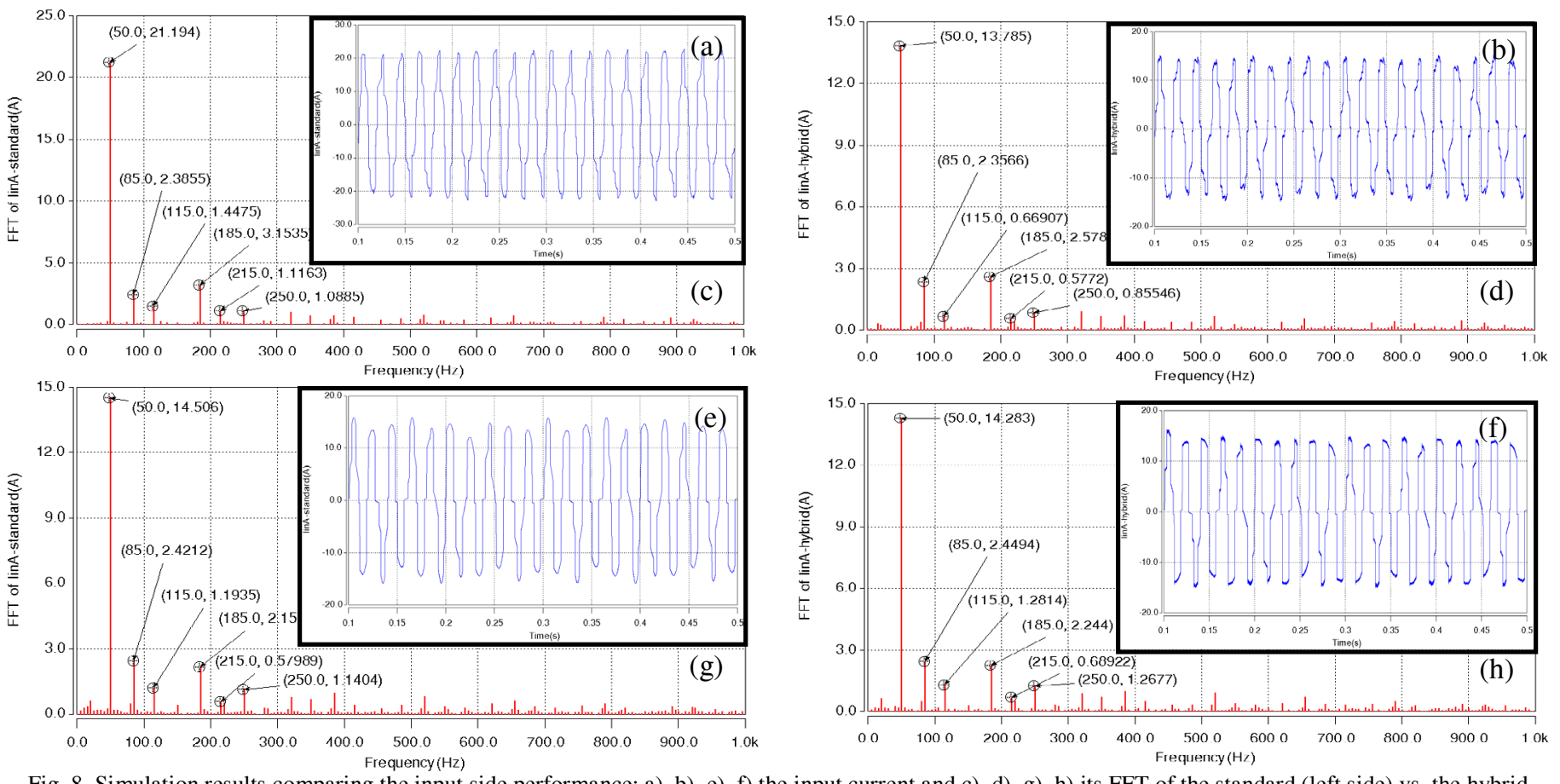

Fig. 8. Simulation results comparing the input side performance: a), b), e), f) the input current and c), d), g), h) its FFT of the standard (left side) vs. the hybrid (right side) cycloconverters operating with (upper row)/without (lower row) circulating current.

which is more visible for the hybrid situation. The operation of the H-bridge inverter is revealed in Fig. $10 \mathrm{~g}$ by the injected PWM voltage waveform and its low pass filtered component.

\section{CONCLUSIONS}

This paper evaluates through simulations and experimentally two standard and two hybrid cycloconverter topologies that operate with and without circulating current. It is shown that even though the cycloconverter that operates with circulating current has better output performance that can be enhanced by the hybrid approach by controlling its circulating current accurately (and therefore improving its input power quality), the voltage rating of the devices needed in the auxiliary H-bridge inverter is high. This aspect, in conjunction to the need of large interphase reactors and the poor input side power quality disqualifies this topology in favour of the hybrid cycloconverter without circulating current, which needs less power devices with smaller voltage rating (smaller power installed) in the auxiliary forced commutated inverter that can improve the output performance but require no additional magnetics.

\section{ACKNOWLEDGMENT}

Support for this work from the EPSRC is gratefully acknowledged (Grant EP/C52652X/1).

\section{APPENDIX A.}

Circuit parameters for simulations: $\mathrm{V}_{\text {in-line }}=415 \mathrm{~V}_{\mathrm{RMS}}, \mathrm{f}_{\mathrm{in}}=$ $50 \mathrm{~Hz}, \mathrm{f}_{\text {out }}=5 \mathrm{~Hz}, \mathrm{~L}_{\text {load }}=0.3 \mathrm{H}, \mathrm{R}_{\text {load }}=13 \Omega ; \mathrm{L}_{\text {IPR }}=2 \times 100 \mathrm{mH}$ (coupled), $\mathrm{R}_{\mathrm{IPR}}=0.05 \Omega ; \mathrm{f}_{\mathrm{sw}-\mathrm{HB}}=5 \mathrm{kHz}, \mathrm{V}_{\mathrm{HB}-\mathrm{DC}}=300 \mathrm{~V} / 250 \mathrm{~V}$ (with/without circulating current), $\mathrm{C}_{\mathrm{dc}-\mathrm{HB}}=8.2 \mathrm{mF}$.

\section{APPENDIX B.}

Circuit parameters for the experimental setup: $\mathrm{V}_{\text {in-line }}=121$ $\mathrm{V}_{\mathrm{RMS}}, \mathrm{f}_{\text {in }}=50 \mathrm{~Hz}, \mathrm{f}_{\text {out }}=5 \mathrm{~Hz}, \mathrm{~L}_{\text {load }}=0.4 \mathrm{H}, \mathrm{R}_{\text {load }}=20 \Omega ; \mathrm{L}_{\text {IPR }}=$ $2 \times 100 \mathrm{mH}$ (coupled); $\mathrm{f}_{\mathrm{sw}-\mathrm{HB}}=5 \mathrm{kHz}, \quad \mathrm{V}_{\mathrm{HB}-\mathrm{DC}}=80 \mathrm{~V} / 75 \mathrm{~V}$ (with/without circulating current), $\mathrm{C}_{\mathrm{dc}-\mathrm{HB}}=8.2 \mathrm{mF}$.

\section{REFERENCES}

[1] B.R. Pelly, "Thyristor phase-controlled converters and cycloconverters", Wiley Interscience, 1971.

[2] W. McMurray, "The Theory and Design of Cycloconverters" Massachusetts Inst. of Tech. Press, Cambridge, MA, 1972.

[3] R. Hagmann, "AC-cycloconverter drives for cold and hot rolling mill applications", IEEE Proc. of IAS'91, Vol.2, pp. 1134-1140, 1991

[4] Y. Tamura, S. Tanaka, S. Tadakuma, "Control method and upper limit of output frequency in circulating-current type cycloconverter", IEEE Int. Semicond. Power Converter Conf., 1982, pp, 313-323.

[5] J. Trautner and A. Wick, "DC Link converter and cyclo-converter-fed AC motors: The concepts and properties of large variable-speed drives," Siemens Rev. (Energy\&Automation-Issue on Large Electric Motor\&VSD), vol. 1, pp. 16-31, 1988.

[6] H. Akagi, "Large static converters for industry and utility applications," Proc. IEEE, Vol. 89, No. 6, pp. 976-983, 2001.

[7] Y. Liu, G.T. Heydt, R.F. Chu, "The Power Quality Impact of Cycloconverter Control Strategies", IEEE Trans. on Power Delivery, Vol.20, No.2, pp.1711-1718, 2005.

[8] P. Syam, P.K. Nandi, A.K. Chattopadhyay, "Effect of output current ripple on the input supply current and the power quality for a cycloconverter-fed drive", Proc. IEE Part-B, EPA, Vol.151, No. 04, pp.425-433, July 2004.

[9] J.R. Rodriguez, J.Pontt, P. Newman, R. Musalem, H. Miranda, L.Moran, "Technical Evaluation and Practical Experience of Highpower Grinding Mill Drives in Mining Applications", IEEE Trans. on Industry Applications, Vol. 41, No. 3, pp. 866-874, 2005.

[10] C. Klumpner, T. Xu, J. Clare, "A New Hybrid Cycloconverter with Smooth Output Voltage Generation Capability and Accurate Control of the Circulating Current”, IEEE Proc. of IECON, pp. 2291-2296, 2006.

[11] T. Xu, C. Klumpner, J. Clare, "Hybrid Cycloconverters: An Exploration of Benefits", Proc. of EPE2007, paper \#479, 2007. 

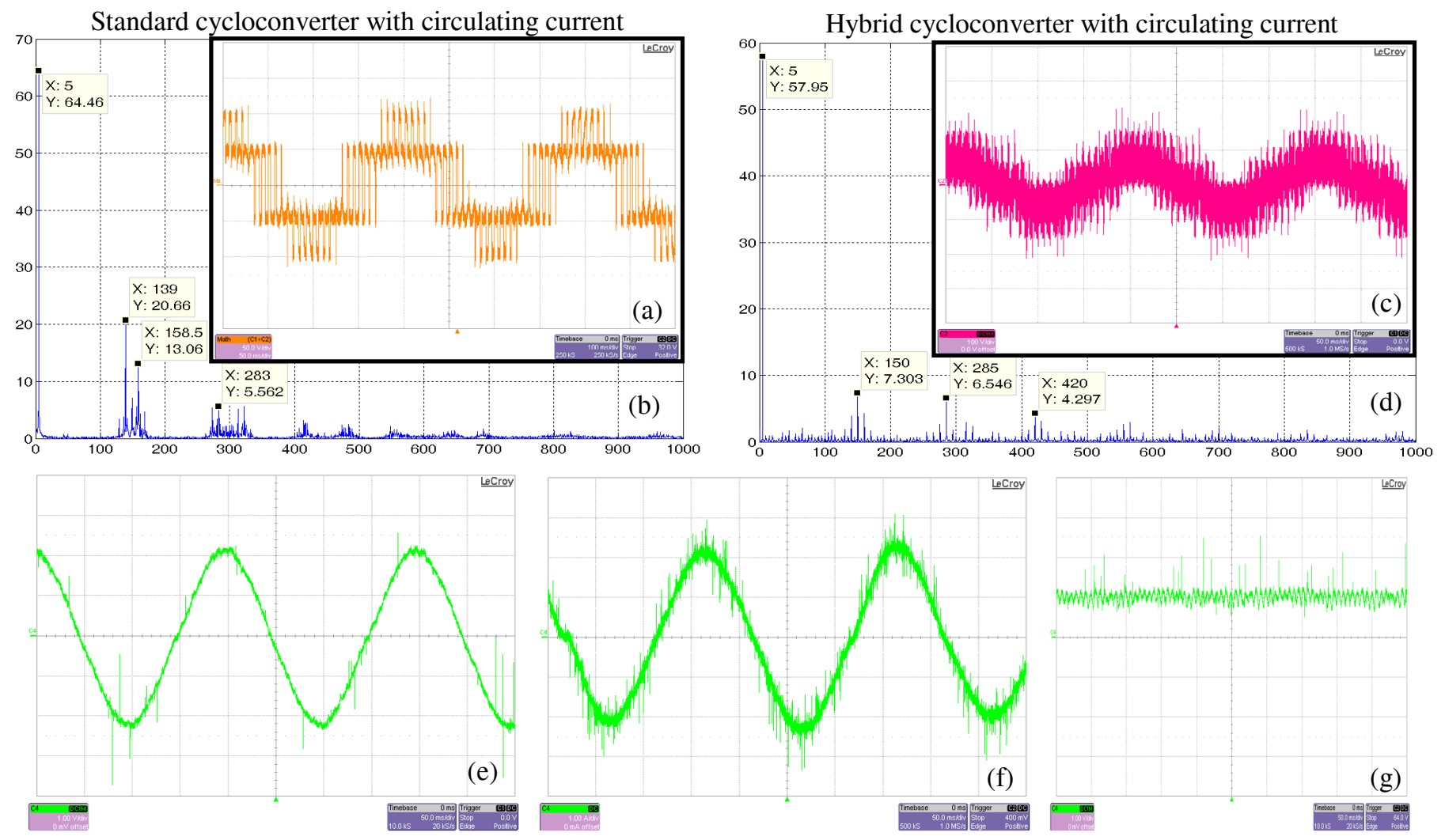

Fig. 9. Experimental evaluation of standard vs. hybrid cycloconverter with circulating current: a), c) output voltage and b), d) its FFT; e), f) the load current; g) the circulating current (measured by disconnecting the load).

Standard cycloconverter without circulating current

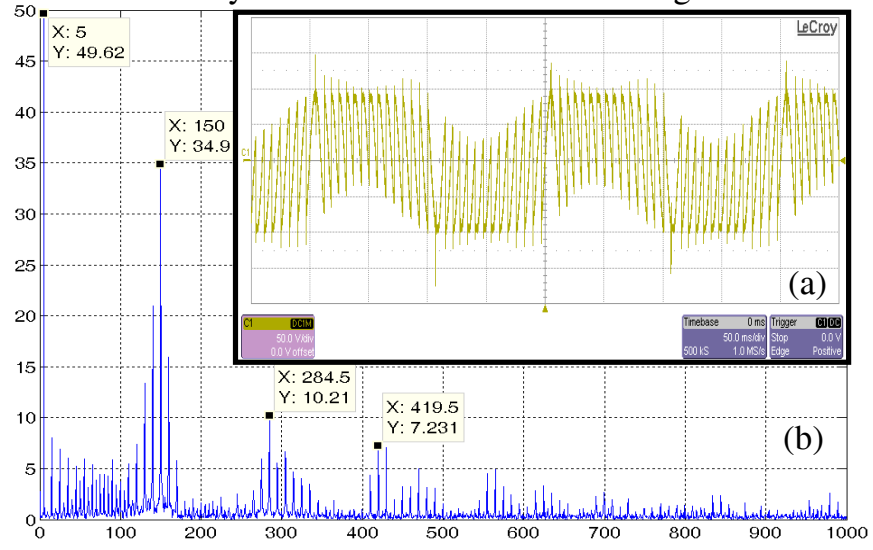

Hybrid cycloconverter without circulating current

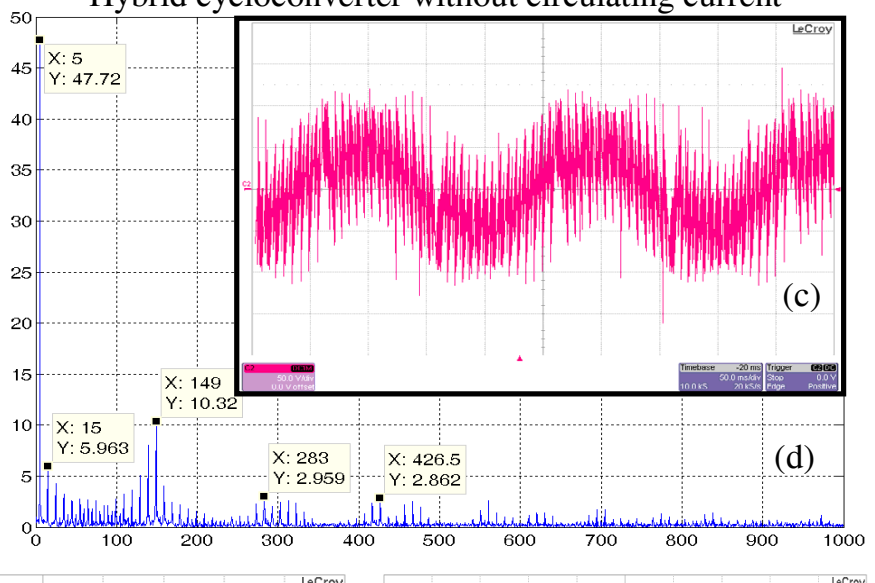

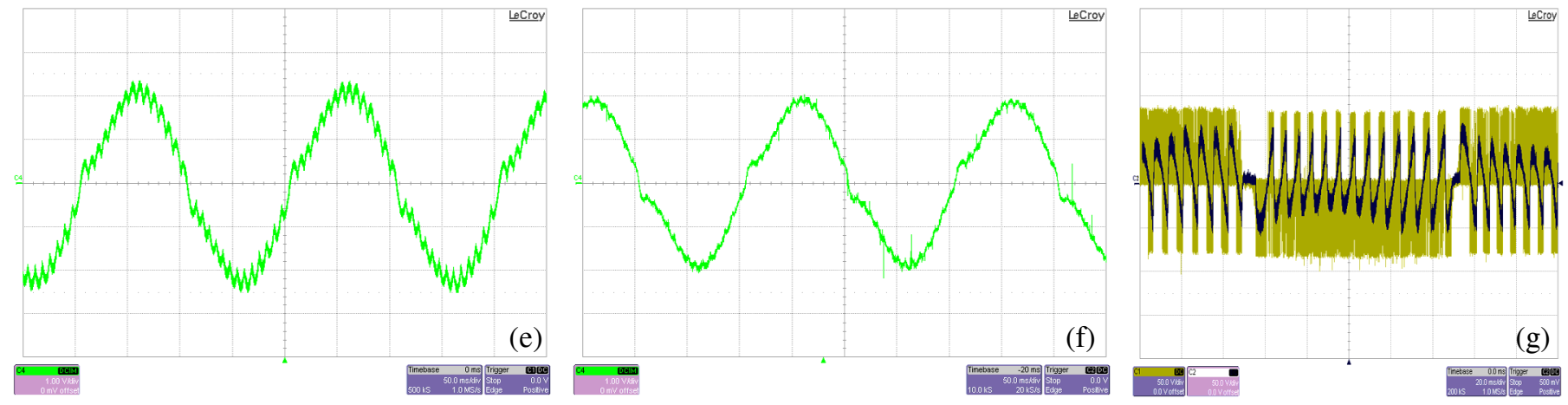

Fig. 10. Experimental evaluation of standard vs. hybrid cycloconverter operating without circulating current: a), c) output voltage and b), d) its FFT; e), f) the load current; g) the voltage injected by the H-bridge inverter. 